\title{
Control of the power quality for a DFIG powered by multilevel inverters
}

\author{
Hachemi Hachemi ${ }^{1}$, Ahmed Allali ${ }^{2}$, Belkacem Belkacem ${ }^{3}$ \\ 1,2 University of Science and Technology of Oran Mohamed Boudiaf, \\ LDDEE, Laboratoire de Développement durable de l'Energie Electrique, Algeria \\ ${ }^{3}$ Institut de Maintenance et de Sécurité Industrielle, Université d'Oran, Algeria
}

\begin{tabular}{l} 
Article Info \\
Article history: \\
Received Aug 23, 2019 \\
Revised Feb 24, 2020 \\
Accepted Mar 25, 2020 \\
\hline Keywords: \\
Doubly fed induction generator \\
DFIG \\
H-BRIDGE \\
Multi-levels inverters \\
PI controllers \\
Stator flux orientation SFOC \\
\hline
\end{tabular}

\begin{abstract}
This paper treats the modeling, and the control of a wind power system based on a doubly fed induction generator DFIG, the stator is directly connected to the grid, while the rotor is powered by multilevel inverters. In order to get a decoupled system of controlfor an independently transits of active and reactive power, a vector control method based on stator flux orientation SFOC is considered: Direct vector control based on PI controllers. Cascaded H-bridge CHBI multilevel inverters are used in the rotor circuit to study its effect on supply power quality. All simulation models are built in MATLAB/Simulink software. Results and waveforms clearly show the effectiveness of vector control strategy. Finally, performances of the system will tested and compared for each levels of inverter.
\end{abstract}

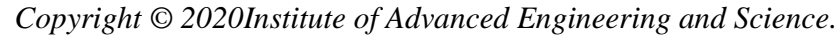
All rights reserved.

\section{Corresponding Author:}

Hachemi Hachemi,

University of Science and Technology of Oran Mohamed Boudiaf,

El Mnaouar، BP 1505, Bir El Djir 31000, Algeria.

Email: h.hachemi@yahoo.fr

\section{INTRODUCTION}

The generation of electricity that comes from nuclear power and fossil natural resources, pose continued problems whose importance is growing over the years; as the nuclear untreatable waste and disappearance expected in the $21^{\text {st }}$ century, for major source of fossil energy. Environmental constraints on atmospheric emissions of greenhouse gases has led researchers a way of generating clean, economic and sustainable electricity [1].

Various studies carried out in this context have shown that far-reaching changes are essential in energy strategies to ensure better management of the production, transformation, distribution and use of energy [2]. From this perspective, controlling energy in a broad sense constitutes an important challenge in the development of sustainable energy. Energy efficiency and renewable energies are therefore interesting avenues for more sustainable energy development and are considered to be among the most environmentally friendly components, particularly in the fight against climate change [3]. Thus, the modes of production based on the transformation of renewable energy (solar, wind ...) are expected to be increasingly used in the context of sustainable development, and thanks to recent developments of power electronics and micro processing.

The production area of variable speed wind energy has in recent years a boom. A great attention is paid today to doubly fed machine DFIM for various applications suchas generator for wind energy. This interest is mainly due to the fact of accessibility for its rotor and therefore the possibility of supplying a converter as well as the stat side gold on the rotor side.

Power-electronic converters have been developed for integrating wind power with the electric grid. The use of power-electronic converters allows for variable-speed operation of the wind turbine, and enhanced 
power extraction. In variable-speed operation, a control method designed to extract maximum power from the wind turbine and provide constant grid voltage and frequency is required [4].

In this paper, a variable-speed wind turbine is considered with DFIG and a multilevel cascaded H-Bridge Inverter CHBI. Multilevel inverters are AC-DC-AC converters, well suited for medium and high-power applications [5] due to their ability to meet the increasing demand of power ratings and power quality associated with reduced harmonic distortion, lower electromagnetic interference, and higher efficiencies when compared with the conventional two or three level topology [6]. The increasing number of voltage levels lead to the production of high-power quality waveforms [7], causing the total harmonic distortion THD to be lower. Multilevel converters are a good tradeoff solution between performance and cost in wind high-power systems [8].

The most typical connection diagram of this DFIG is to connect stator directly to the grid, while the rotor is supplied through a controlled power converter. This solution is more attractive for all applications where speed variations are limited around the synchronous speed because this area operating presents low slip, and therefore the converter associated with the rotor has to be treated only for a fraction of 20 to $30 \%$ of the nominal conversion system power; this means that the losses in the converter are reduced (power supplied to the rotor is low) and the cost thereof is reduced. That is why we find this machine in high power variable speed and constant frequency for production systems. A second reason is the possibility of controlling the active and reactive power in the stator via the control of the power converter [9].

Further variable speed wind turbine is modeled to find a relationship between the electromagnetic torque and the mechanical wind speed. After describing mechanical and electrical model of the DFIG in section 3, a vector control method based on stator flux orientation SFOC is considered: direct vector control based on PI controllers. The sinus pulse wave modulation (SPWM) control strategyfor multilevel invertersis given in section 4. Finally, simulation and results are presented; performances of the system are then evaluated.

\section{WIND TURBINE MODEL}

Mechanical power available on the shaft of a wind turbine is expressed by [10]:

$$
P_{v}=\frac{1}{2} \rho S v_{v}^{3}=\frac{1}{2} \rho \pi R^{2} v_{v}^{3}
$$

where:

$\rho$ :air density $\left(1.25 \mathrm{Kg} / \mathrm{m}^{3}\right)$;

$R$ : Blade length in meters;

$V_{v}:$ wind velocity in $\mathrm{m} / \mathrm{s}$.

The aerodynamic power extracted from wind turbine canbe calculated as:

$$
\begin{aligned}
& P_{\text {Turb }}=C_{p} P_{v}=\frac{1}{2} \rho S v_{v}^{3}=\frac{1}{2} \rho \pi R^{2} v_{v}^{3} \cdot C_{p}(\lambda, \beta) \\
& \lambda=\frac{\Omega_{\text {Turb }} \cdot R}{v_{v}}
\end{aligned}
$$

where:

$\mathrm{C}_{\mathrm{p}}$ : Power coefficient;

$\beta$ : Pitch angle (deg);

$\lambda:$ Tip speed ratio;

$\Omega$ Turb : Turbine speed (rd/s).

No wind turbine could convert more than $59 \%$ of the kinetic energy of the wind into mechanical energy turning a rotor [11]. This is known as the Betz limit, and it is the theoretical maximum coefficient of power for any wind turbine: $C_{p} \max =16 / 27 \approx 0.593$. The multiplier is mathematically modeled by the following equations:

$$
\left\{\begin{array}{c}
T_{m}=\frac{T_{\text {Turb }}}{G} \\
\Omega_{\text {Turb }}=\frac{\Omega_{m}}{G} \\
J_{T}=\frac{J_{\text {Turb }}}{G^{2}}+J_{g} \\
T_{\text {Turb }}=\frac{P_{\text {Turb }}}{\Omega_{\text {Turb }}}
\end{array}\right.
$$


where:

$\Omega_{t u r b}, \Omega_{m}$ : Turbine speed respectively before and afterthe multiplier; $T_{t u r b}$ : aerodynamic torque; $T_{m}$ : torque after the multiplier; $G$ : Gear ratio; $J_{g}$ : Generator inertia; $J_{T}$ : Total inertia; $J_{T u r b}$ : Turbine inertia.

The fundamental equation of dynamics to determine the evolution of the mechanical speed from the total mechanical torque $T_{m e c}$ applied to the rotor:

$$
J_{T} \frac{d \Omega_{m e c}}{d t}=T_{m e c}=T_{m}-T_{e m}-C_{f} \Omega_{m e c}
$$

where:

$T_{e m}$ : Electromagnetic torque; $C_{f}$ : Viscous friction coefficient.

\subsection{Modeling of the DFIG, Park's model}

The d-q axis representation of DFIG is used for modeling, considering flux as variable based on Park's model. All rotor quantities are referred to stator side. The DFIG model represented by voltage (6). The stator and rotor side flux linkage equations are given as [12-14]:

$$
\left\{\begin{array}{c}
V_{s d}=R_{s} I_{s d}+\frac{d \Phi_{s d}}{d t}-\omega_{s} \Phi_{s q} \\
V_{s q}=R_{s} I_{s q}+\frac{d \Phi_{s q}}{d t}+\omega_{s} \Phi_{s d} \\
V_{r d}=R_{r} I_{r d}+\frac{d \Phi_{r d}}{d t}-\left(\omega_{s}-\omega_{r}\right) \Phi_{r q} \\
V_{r q}=R_{r} I_{r q}+\frac{d \Phi_{r q}}{d t}+\left(\omega_{s}-\omega_{r}\right) \Phi_{r d}
\end{array}\right.
$$

The stator and rotor flux can be expressed as:

$$
\left\{\begin{array}{l}
\Phi_{s d}=L_{s} I_{s d}+L_{m} I_{r d} \\
\Phi_{s q}=L_{s} I_{s q}+L_{m} I_{r q} \\
\Phi_{r d}=L_{r} I_{r d}+L_{m} I_{s d} \\
\Phi_{r q}=L_{r} I_{r q}+L_{m} I_{s q}
\end{array}\right.
$$

Electromagnetic torque is also expressed in terms of currents and flux:

$$
C_{e m}=p \frac{L_{m}}{L_{s}}\left(\Phi_{s d} I_{q r}-\Phi_{s q} I_{d r}\right)
$$

where:

$R s, R r$, are respectively the stator and rotor resistances; $\mathrm{L}_{\mathrm{s}}, \mathrm{L}_{\mathrm{r}}$ : inductances of the stator and rotor windings; $L_{m}$ is the mutual inductance; Vds, Vqs, Vdret Vqr: Direct and quadrate components of the space phasors of the stator and rotor voltages; Ids, Iqs, Idr, Iqr: Direct and quadrate components of the space phasors of the stator and rotor currents; $\varphi d s, \varphi q s, \varphi d r e t \varphi q r$ : Direct and quadrate components of the space phasors of the stator and rotor flux respectively;

$\omega s$ : Rotational speed of the synchronous reference frame;

$\varpi r$ : Rotor speed,

p: Number of pair poles.

Active and reactive powers at the stator $(P s, Q s)$, and the rotor $(P r, Q r)$ are defined as [15-16]:

$$
\left\{\begin{array}{l}
P_{s}=V_{s d} I_{s d}+V_{s q} I_{s q} \\
Q_{s}=V_{s q} I_{s d}-V_{s d} I_{s q} \\
P_{r}=V_{d r} I_{d r}+V_{q r} I_{q r} \\
Q_{r}=V_{q r} I_{d r}-V_{d r} I_{q r}
\end{array}\right.
$$

\subsection{Control strategy of the DFIG}

Once the DFIG is connected to an existing grid, the transit of active and reactive powers must be controlled separately. To obtain a decoupled powers control of DFIG, the method based on field orientation 
can be regarded as the efficient one. The principle of this method consists to orientate the stator flux in such a way that the stator flux vector points into d-axis direction; this approach is realized by setting the quadratic component of the stator flux to the null value, detailed representation is show in Figure $1[17,18]$.

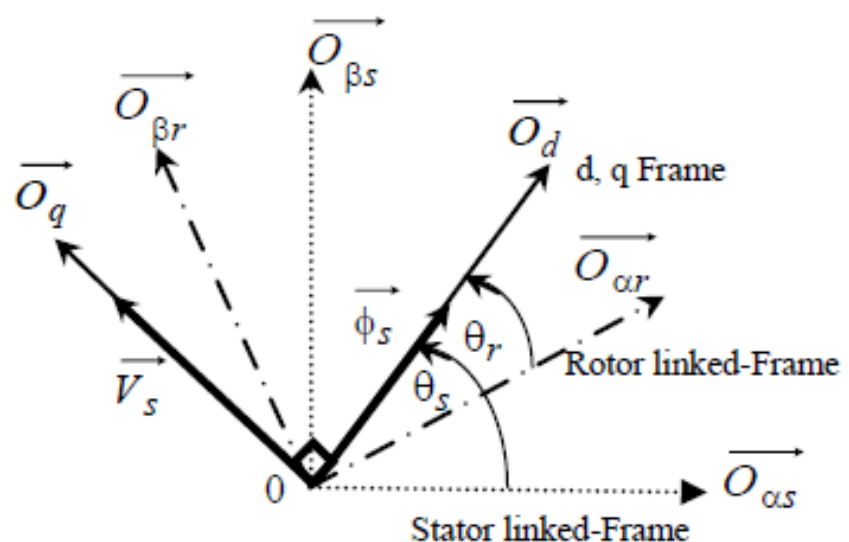

Figure 1. Stator flux orientation

The stator fluxes of (6) will be simplified as follows:

$$
\left\{\begin{array}{c}
\Phi_{s d}=L_{s} I_{s d}+L_{m} I_{r d}=\Phi_{s} \\
\Phi_{s q}=L_{s} I_{s q}+L_{m} I_{r q}=0
\end{array}\right.
$$

The stator resistance will be neglected, for medium power machines used in WECS; the stator voltage vector is consequently in quadrate advance in comparison with the stator flux vector.

$$
\left\{\begin{array}{c}
V_{s d}=0 \\
V_{s q}=\omega_{s} \Phi_{s}=V_{s}
\end{array}\right.
$$

Using (10), we can establish the connection between the rotor and stator currents:

$$
\left\{\begin{array}{c}
I_{s d}=-\frac{L_{m}}{L_{s}} I_{r d}+\frac{\emptyset_{s}}{L_{s}} \\
I_{s q}=-\frac{L_{m}}{L_{s}} I_{r q}
\end{array}\right.
$$

Using (11) and (12), the stator active and reactive power and rotor voltage are given by:

$$
\left\{\begin{array}{c}
P_{s}=V_{s} I_{s q}=-V_{s} \frac{L_{m}}{L_{s}} I_{r q} \\
Q_{s}=V_{s} I_{s d}=-V_{s} \frac{L_{m}}{L_{s}} I_{r d}+\frac{V_{s}^{2}}{L_{s} w_{s}}
\end{array}\right.
$$

For controlling the DFIG, established expressions showing the relationship between current and rotor voltages will be applied to it.

$$
\left\{\begin{array}{c}
V_{r d}=R_{r} I_{r d}+\left(L_{r}-\frac{L_{m}^{2}}{L_{s}}\right) \frac{d I_{r d}}{d t}-g w_{s}\left(L_{r}-\frac{L_{m}^{2}}{L_{s}}\right) I_{r q} \\
V_{r q}=R_{r} I_{r q}+\left(L_{r}-\frac{L_{m}^{2}}{L_{s}}\right) \frac{d I_{r q}}{d t}+g w_{s}\left(L_{r}-\frac{L_{m}^{2}}{L_{s}}\right) I_{r d}+g \frac{L_{m} V_{s}}{L_{s}}
\end{array}\right.
$$

By considering $\sigma$ as the cross coupling term, (14) can be rewrite as: 


$$
\left\{\begin{array}{c}
V_{r d}=R_{r} I_{r d}+L_{r} \sigma \frac{d I_{r d}}{d t}-g \sigma w_{\sigma} L_{r} I_{r q} \\
V_{r q}=R_{r} I_{r q}+L_{r} \sigma \frac{d I_{r q}}{d t}+g \sigma w_{s} L_{r} I_{r d}+g \frac{L_{m} V_{s}}{L_{s}} \\
\sigma=1-\frac{L_{m}^{2}}{L_{r} L_{s}}
\end{array}\right.
$$

The block diagram representing the internal model of the system is shown in Figure 2. Field oriented control of the DFIG can then be applied with the active and reactive power considered as variables to be controlled. The input blocks relating $V_{r d}$ to $V_{r q}$ represent the simplified rotor converter model. Knowing (13) and (15), it is then possible to synthesize the regulators [19].

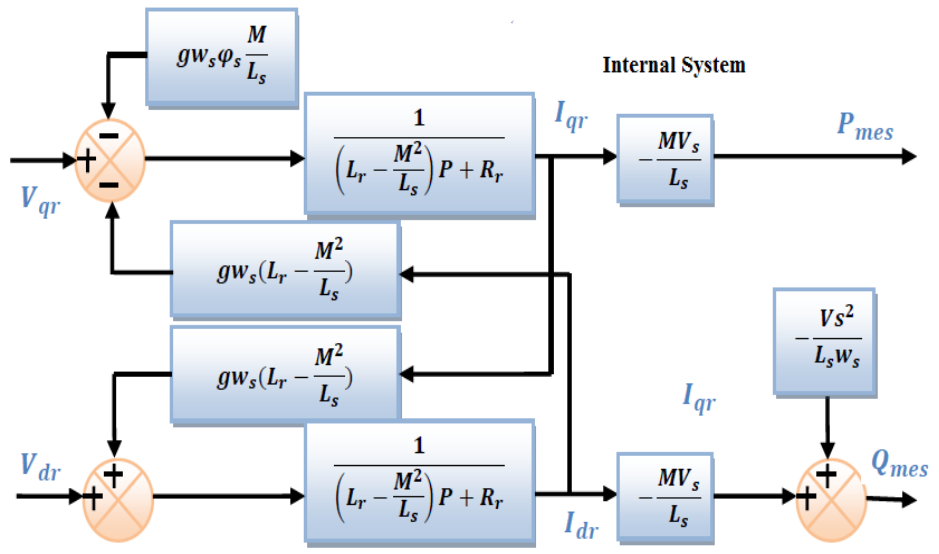

Figure 2. Block diagram of the system to regulate

In order to improve the last command, we will introduce an additional control loop at the currents to eliminate the static error while preserving the dynamics of the system, then, two additional PI controllers are added to regulate the active and reactive powers. So, we need sixcurrents sensors, three to control the rotor currents $\left(i_{a r}, i_{b r}\right.$ and $\left.i_{c r}\right)$ and three associated with three voltage sensors to measure the stator powers $P_{s}$ and $Q_{s}$. The active power PI controller regulates the rotor current reference iqr from the error between the active power measured $P_{s}$ and the desired active power $P_{\text {ref }}$. Furthermore, the reactive power PI controller regulates the rotor current reference idr from the error between the reactive power measured $Q_{s}$ and the desired reactive power $Q_{\text {ref. }}$ The closed loop control of active and reactive powers is presented in Figure 3:

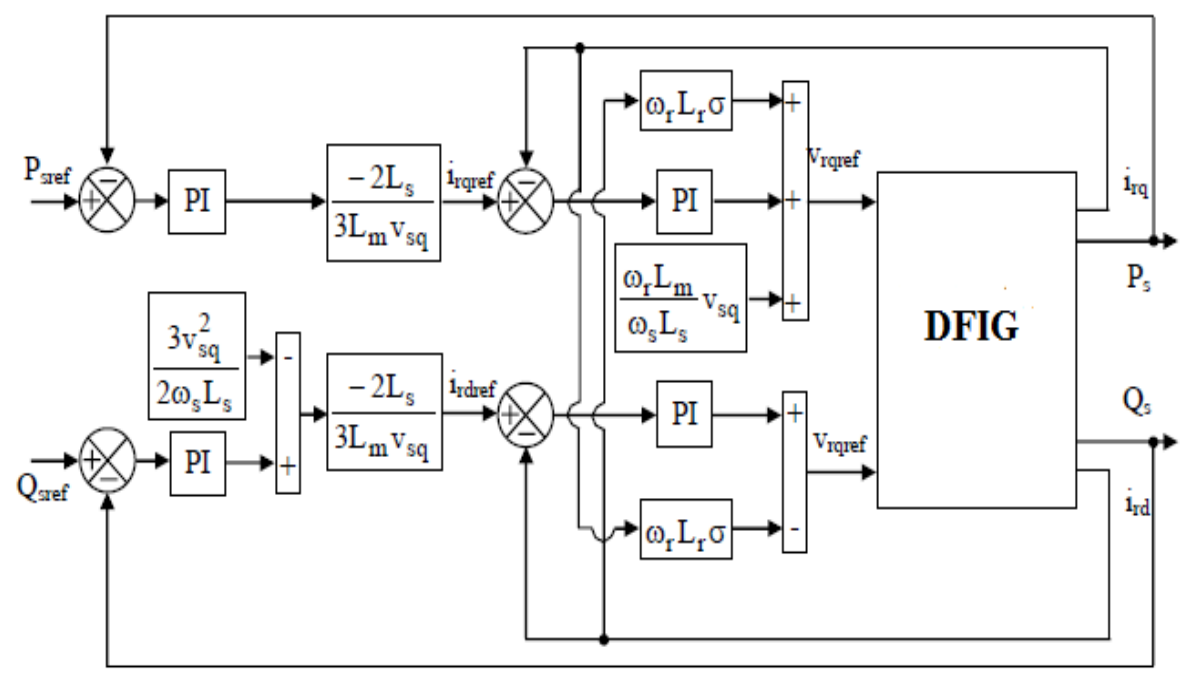

Figure 3. Closed loop control of active and reactive powers 


\section{CASCADED H-BRIDGE INVERTER CHBI THEORY}

Several multilevel topologies used for grid connection have been proposed in [20, 21]. Multilevel converter structures have three major classifications; neutral point clamped (NPCor diode clamped), flying capacitor (FC or capacitor clamped), and cascaded H-bridge inverter CHBI, with isolated DC source Figure 4. Compared with the latter two, the multilevel CHBI has many distinct advantages:

- Switch devices required are less under the same switching frequency and level number.

- The harmonic content is lower in the output voltage for a given switching frequency.

- Modularized circuit layout and packaging is possible because each cell has the same structure, and there are no extra clamping diodes as in the case of diode clamped topology, or voltage balancing capacitors as in the case of the capacitor clamped topology [22].

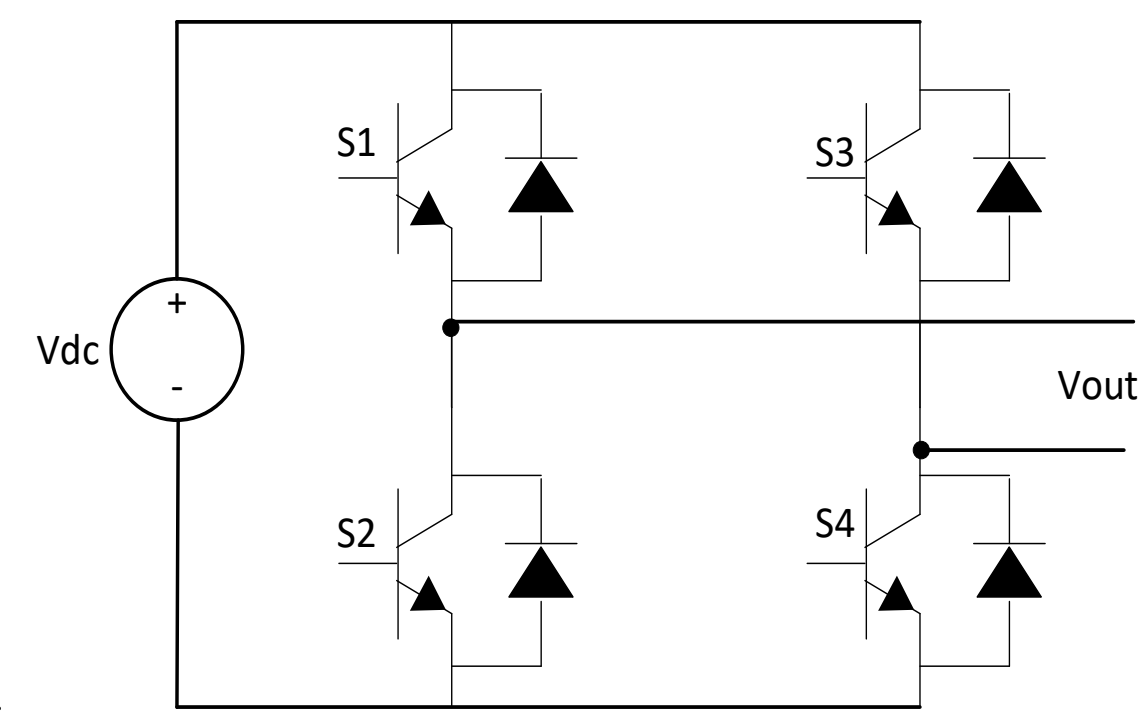

Figure 4. Single phase H-bridge inverter

\subsection{Theory of cascaded $\mathrm{H}$-Bridge multilevel inverter}

The cascaded $\mathrm{H}$ bridge multilevel inverter circuit consists of individual $\mathrm{H}$-bridge cells which are fed by individual dc supply. Each H-bridge cell contains four switches. In this topology, IGBT is used as switch because of its low switching losses. Each H-bridge generates three different output voltages, $+V d c, 0$ and $-V d c$ using various combinations of switching with the four switches [22, 23]. The switching tableof the three level CHB is given in Table 1.

Table 1. Switching table for 3-level CHB inverter

\begin{tabular}{ccccc}
\hline S1 & S2 & S 3 & S4 & Output Voltage \\
\hline 1 & 0 & 0 & 1 & $V_{d c}$ \\
0 & 1 & 1 & 0 & $-V_{d c}$ \\
0 & 0 & 0 & 0 & 0 \\
\hline
\end{tabular}

Cascaded multilevel inverter is the cascade connection of $\mathrm{N} \mathrm{H}$-bridge inverters. Each H-bridge inverter has the same configuration as a typical single-phase full-bridge inverter. In this topology the number of phase voltage levels at the converter terminals is $2 \mathrm{~N}+1$, where $\mathrm{N}$ is the number ofcells or dc link voltages. The IGBT switches have low block voltage and high switching frequency. Consider the seven level inverter; it requires 12 IGBT switches and three dc sources. The power circuit ofinverter is shown in Figure 5. By closing the appropriate switches, each $\mathrm{H}$-bridge inverter can produce three different voltages: $+V d c, 0$ and $-V d c$. It is also possible to modularize circuit layout and packaging because each level has the same structure, and there are no extra clamping diodes or voltage balancing capacitors. The number of switches is reduced using the newtopology [24, 25]. 


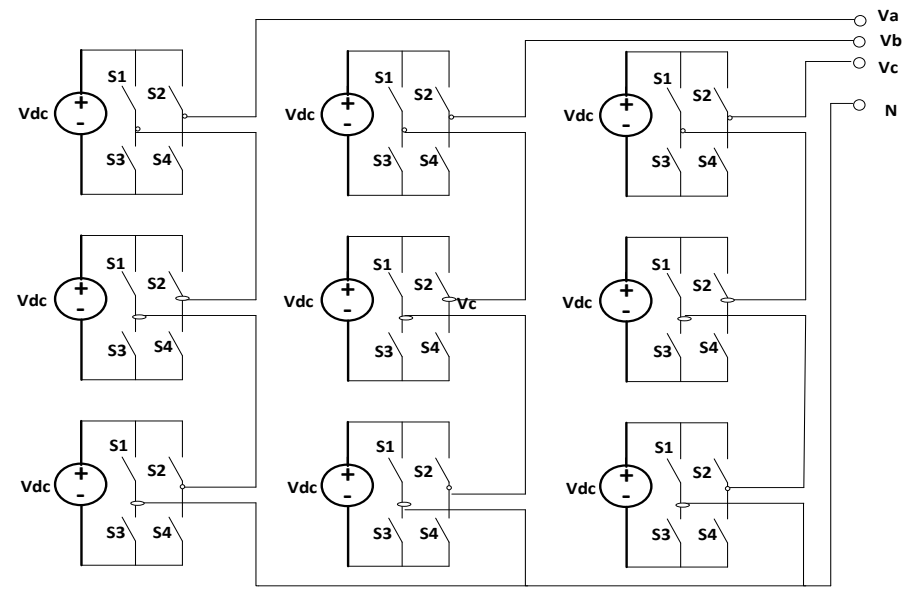

Figure 5. Cascaded H-bridge 7-level inverter

\section{SIMULATION RESULTS}

The system based on a variable speed wind turbine with a doubly fed induction generator DFIG. The simulation is carried out using the MatLab/Simulink software. The DFIG is connected directly to the network through the stator, and controlled by its rotor through a three level CHBI. Simulation results are presented in Figure 6 to Figure 14. They show performances of our system.

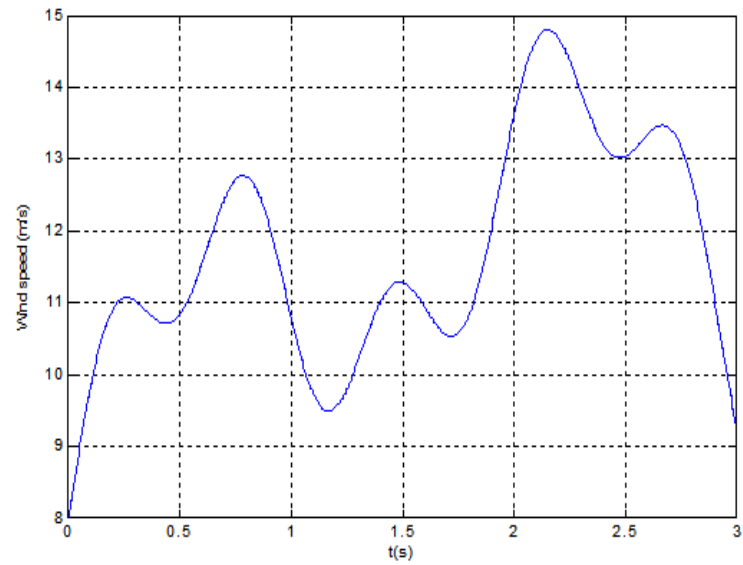

Figure 6. Wind speed

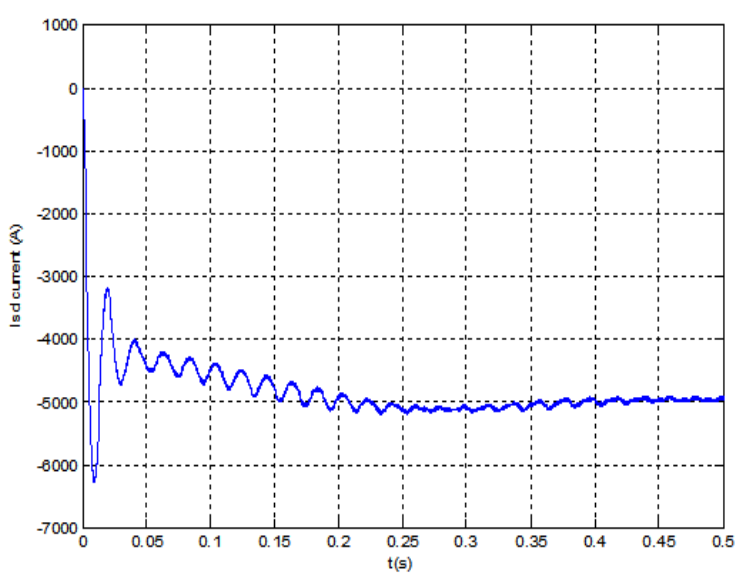

Figure 8. Isd current

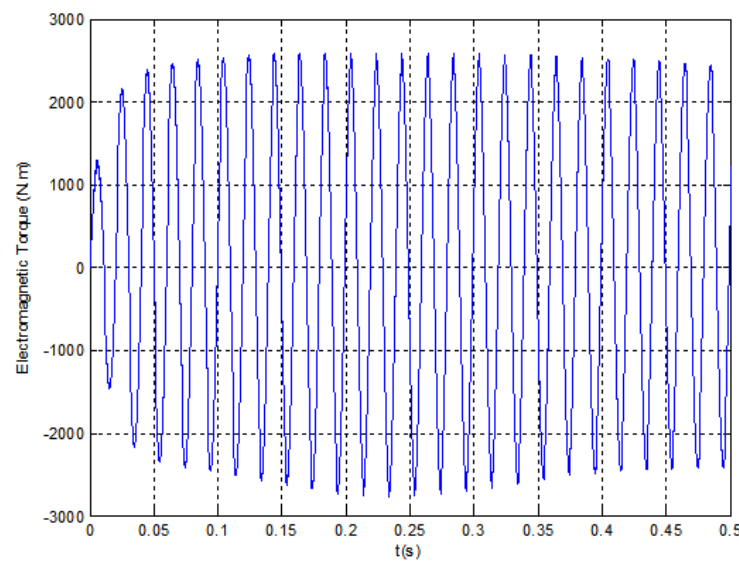

Figure 7. Electromagnetic torque

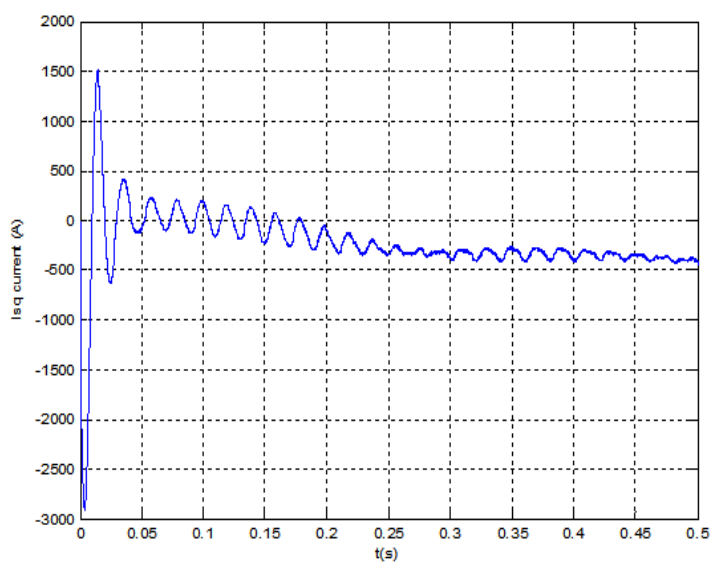

Figure 9. Isq current 


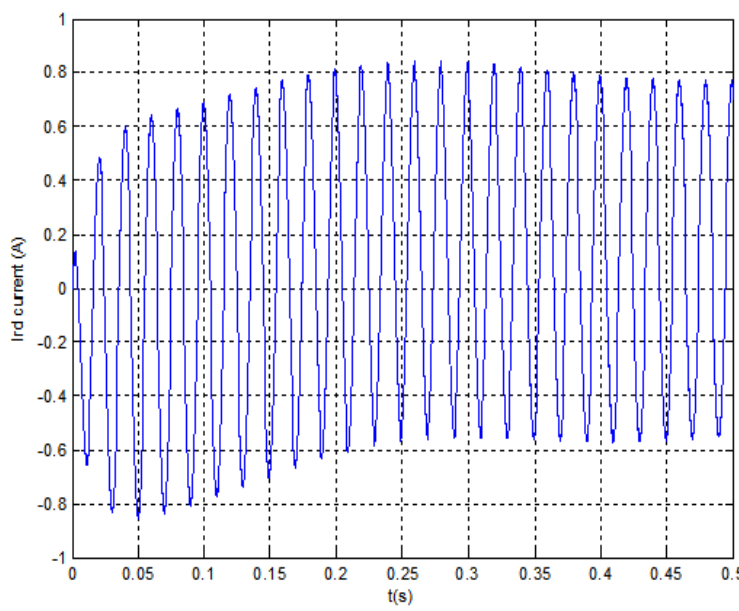

Figure 10. Ird current

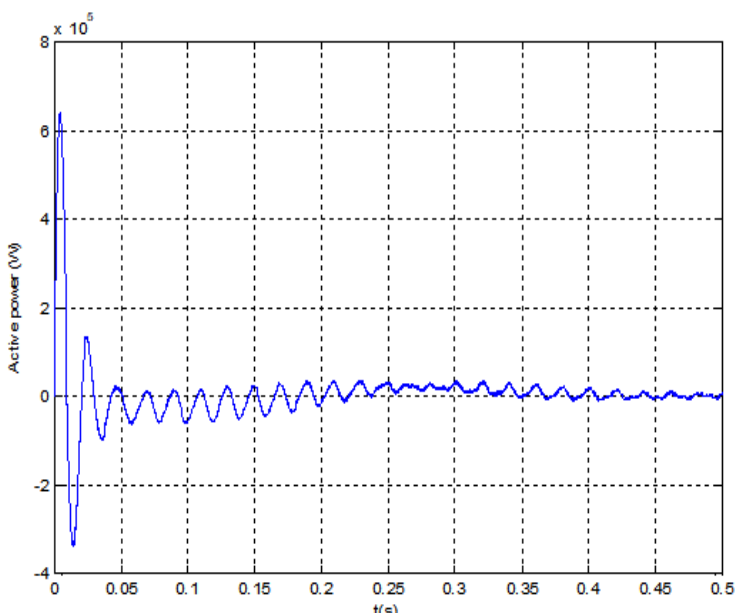

Figure 12. Active power

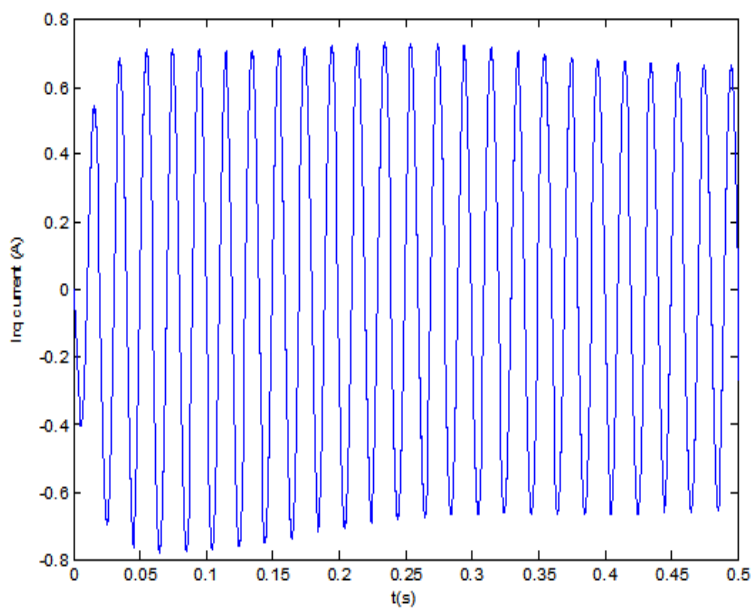

Figure 11. Irq current

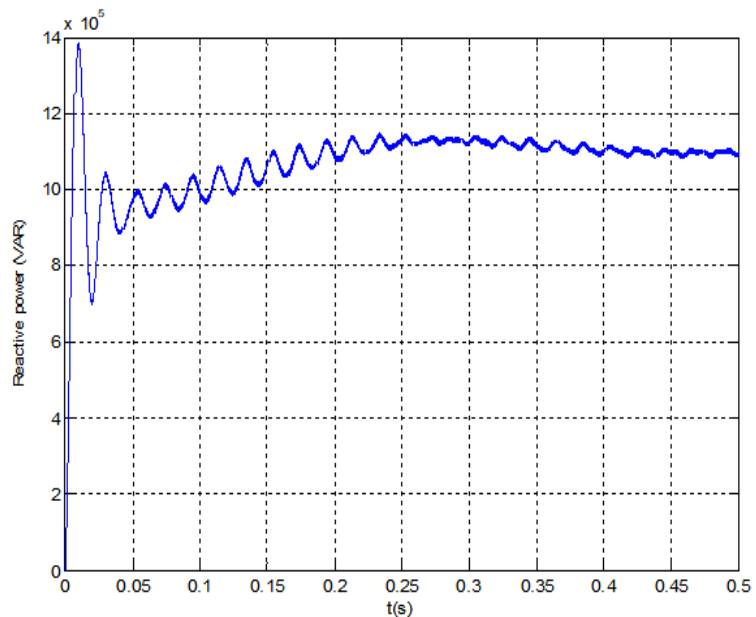

Figure 13. Reactive power

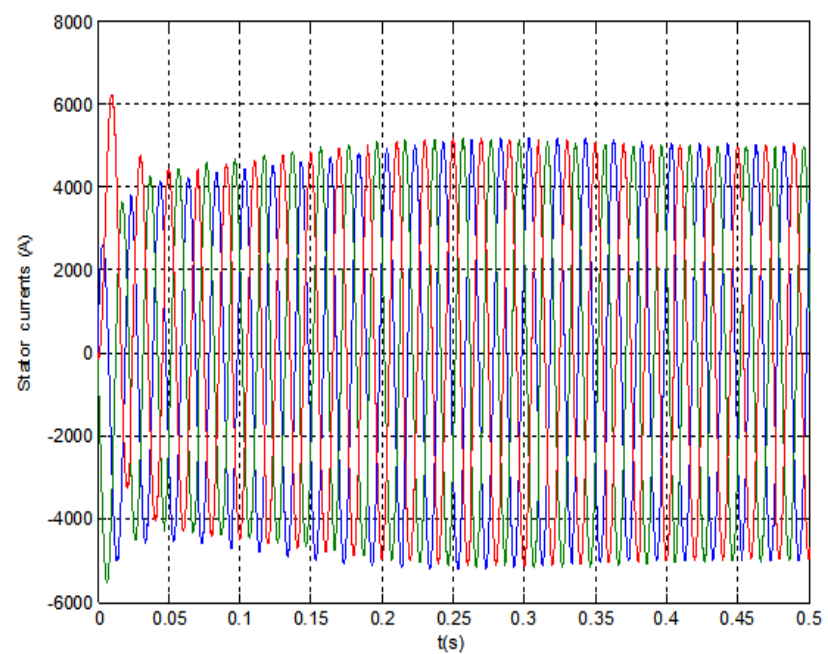

Figure 14. Stator currents 
To control the power exchanged between the stator and the network, one uses the vector control with direct stator flux shown in Figure 15. Simulation results are obtained under various stator active and reactive power steps. The both control strategies with 5 levels CHBI, and 13 levels CHBI separately, are simulated, tested and compared in terms of power reference tracking. We initial simulation at first, with an active power step Psref $=-5 \mathrm{KW}$. At time $\mathrm{t}=0.5 \mathrm{~s}$ to $2 \mathrm{~s}$ an application of the echelon of active power Psref $=-10 \mathrm{KW}$, and after time $\mathrm{t}=2 \mathrm{~s}$ to $3 \mathrm{~s}$ we return at step Psref $=-5 \mathrm{KW}$. The reactive power step is changed from Qsref $=-1$ to $-4 \mathrm{KVAR}$ at the instant $\mathrm{t}=1 \mathrm{~s}$ and again from -4 to $-1 \mathrm{KVAR}$ at the instant $\mathrm{t}=1.5 \mathrm{~s}$; a last variation of the reactive power step at the instant $\mathrm{t}=2.5$ is applied from Qsref $=.-1 \mathrm{KVAR}$. Simulation results are shown in Figure 16 to Figure 19.

It can be seen that multilevel CHBI can control the active and reactive powers of DFIG with a very fast time response. However, the ripples in powers are more significant from control with 5 levels CHBI. To observe the effectiveness of the proposed control strategy, we increased levels of CHBI gradually up to 13 levels. In order to produce quality energy, it is apparent that the control with 13 levels CHBI, harmonics are almost eliminated. Thus, we estimate that these powers injected into the network will have no significant impact.

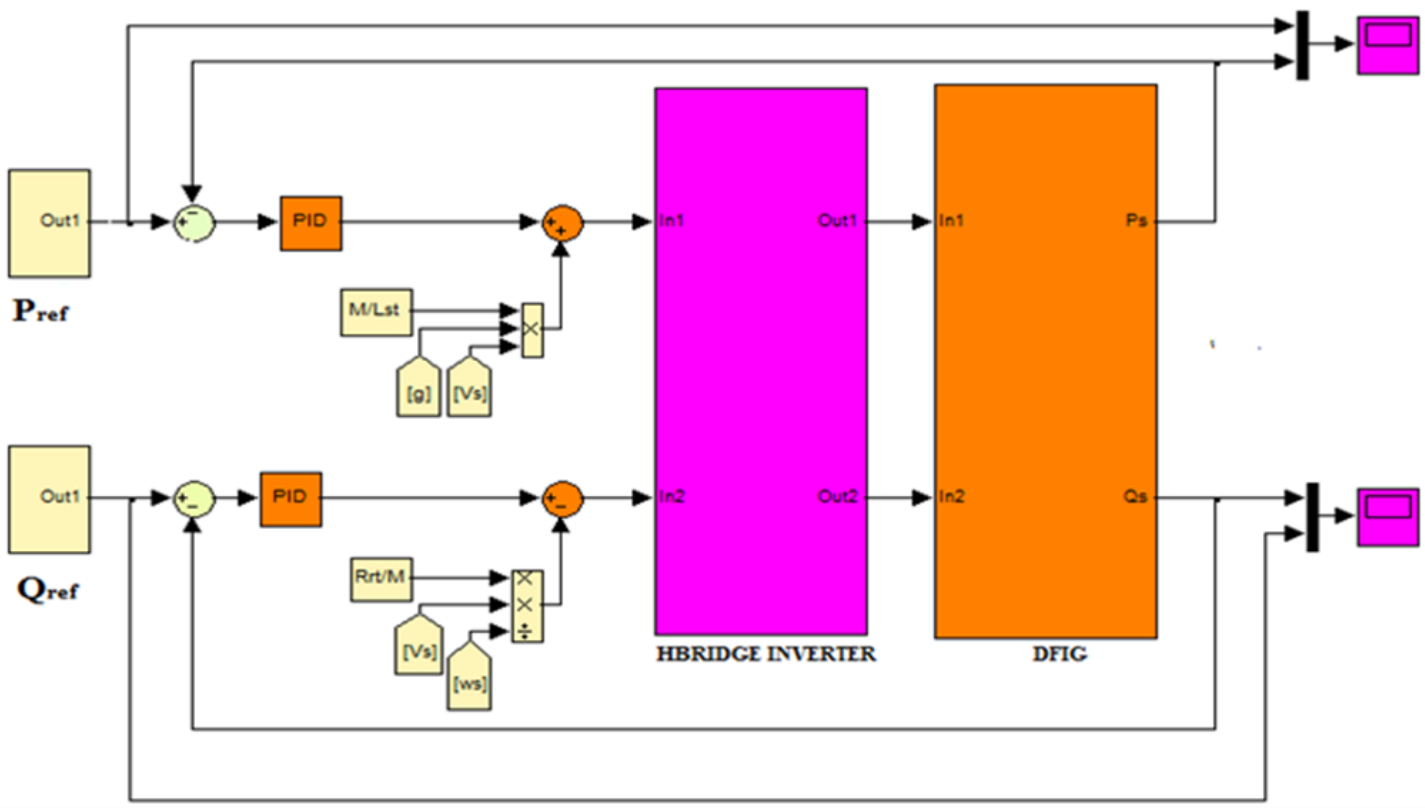

Figure 15. Block diagram of DFIG power control Si tu peux le changer sous forme de bloc c'est mieux
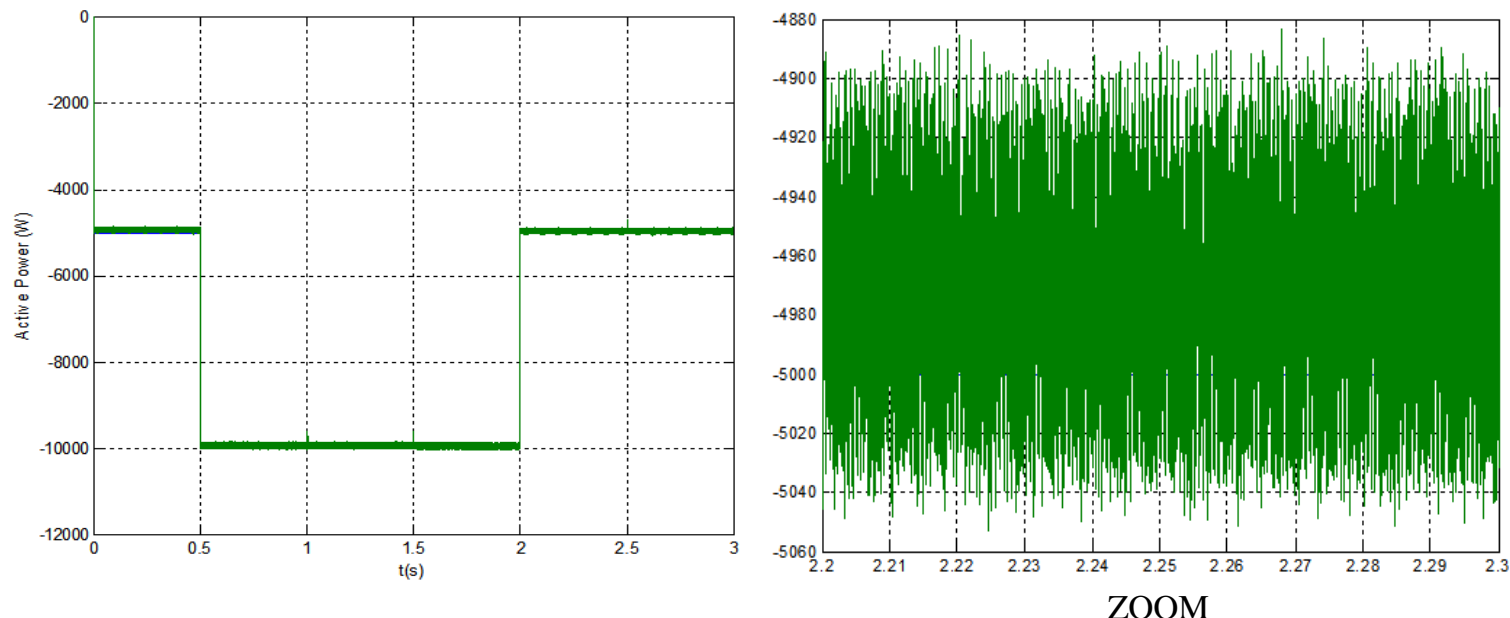

Figure 16. Reel and reference active power with 5 levels CHBI 

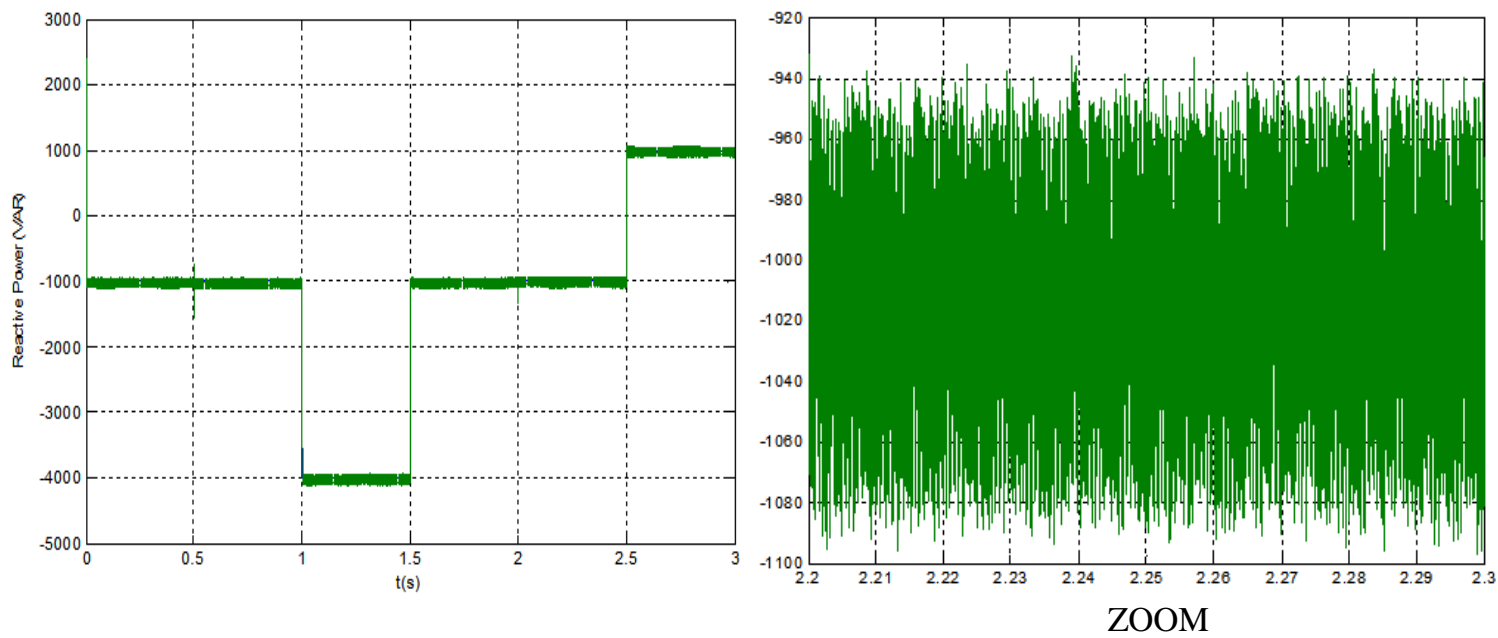

Figure 17. Reel and reference reactive power with 5 levels CHBI
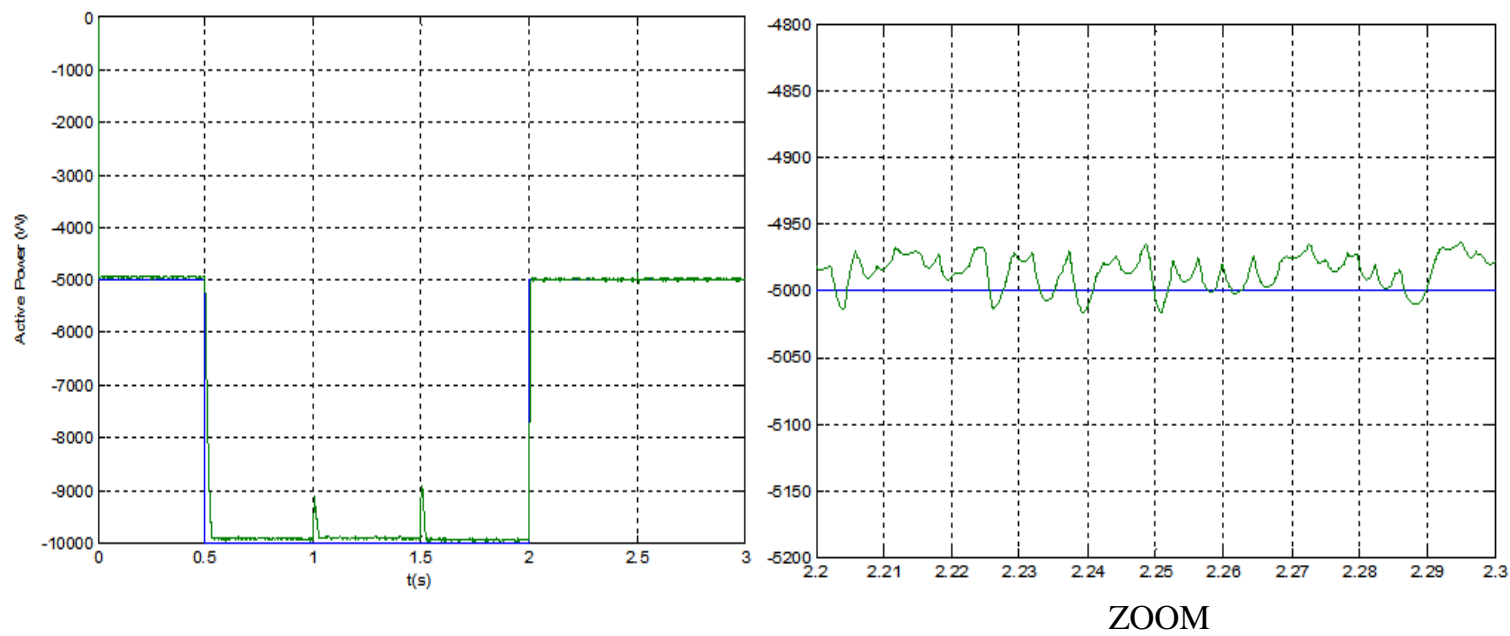

Figure 18. Reel and reference active power with 13 levels CHBI
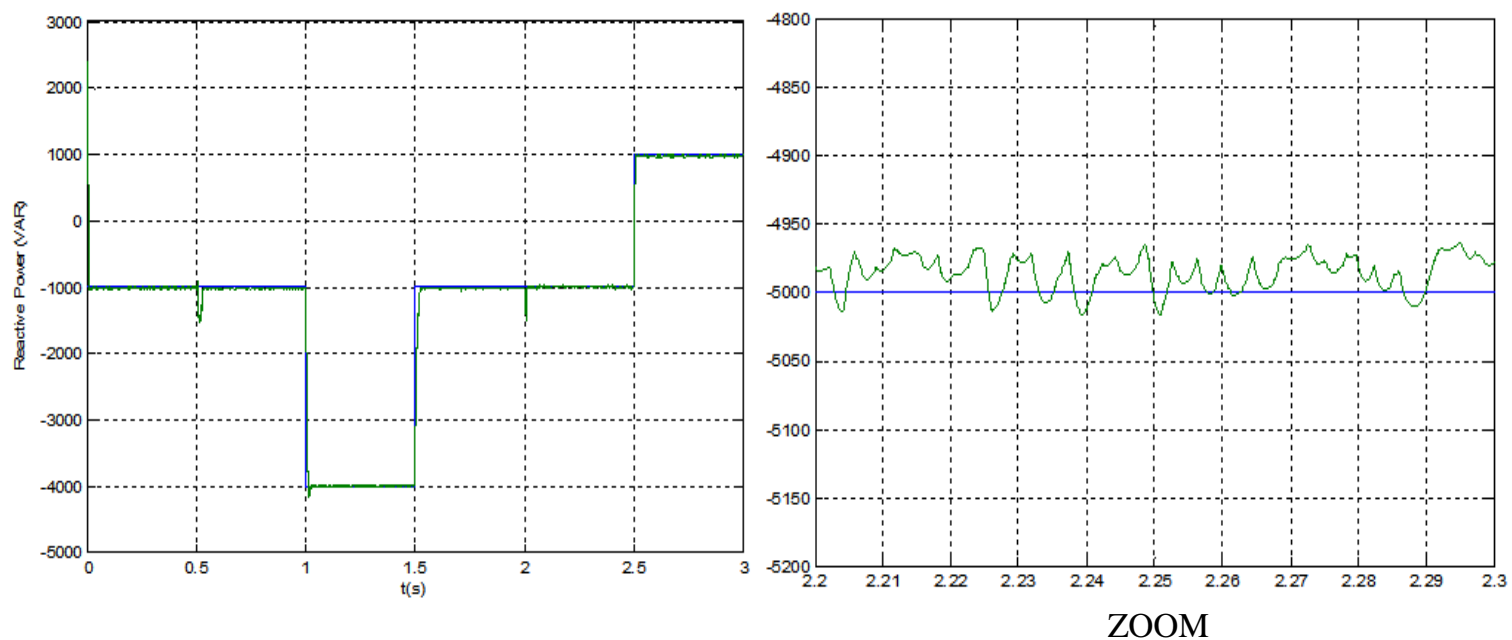

Figure 19. Reel and reference reactive power with 13 levels CHBI 


\section{CONCLUSION}

The aim of this work is to model and control the doubly fed induction generator DFIG based wind energy conversion system powered by multitier inverters with cascaded H-Bridge structure, to increase the power transferred to the network. In this context, a control of the powers of the wind system was carried out. For adjusting the energy quality supplied by the DFIG, vector control by orientation of the stator flow that makes the system similar to that of the DC machine was applied. To be able to directly control the active and reactive DFIG power through multi-level inverters; our strategy was to apply vector control, with a configuration of H. BRIDGE inverters; and then increase their levels, in order to improve the quality of the energy delivered by the DFIG; we thus determined the most efficient system for the different configurations proposed.The global model of our system is at first established. Furthermore, a vector control strategy of the DFIG to perform power reference tracking to machine parameters variation. The structure using the DFIG has a best advantage in terms of high power output, in variable speed operation, while reducing the size of the static converters. Despite this, the use of multilevel converters seems necessary especially for high power wind turbines. These converters increase the power transmitted to the power grid by reducing the current ripple and the harmonic content of the output voltages. This increase is done by means of the voltage, which makes it possible to reduce the losses of power in the lines. The results show that, using multilevels CHBI, the quality of produced energy is improved, in fact the harmonics that decrease the efficiency of the system are extremely diminished.

\section{REFERENCES}

[1] A. Dendouga, "Contrôle des puissances active et réactive de la machine asynchrone à double alimentation," Thèse de doctorat, Université de Batna, 2010.

[2] Patrick Piro, "Guide des énergies vertes pour la maison," Livre éditions : Terre vivante, L'écologie pratique, 2006.

[3] "Evolution et tendances de la demande mondiale en énergie," [Online]. Available: http://web.archive.org/web/20080509052730/www.lenergiecreative.com/ (section "énergie et planète").

[4] Baroudi, J. A, Dinavahi, V and Knight, A. M, "A review of power converter topologies forwind generators," Renew Energy, vol. 32, no. 14, pp. 2369-2385, 2007

[5] Lai, J. S and Peng F. Z., "Multilevel converters. A new breed of power converters," IEEE Transactions on industry applications, vol. 32, no. 3, pp. 509-517, 1996

[6] Abbes, M, Belhadj, J and Bennani, A. B. A, "Design and control of a direct drive wind turbine equipped with multilevel converters," Renew Energy, vol. 35, no. 5, pp. 936-945, 2010.

[7] Babaei. E, Hosseini. S. H, Gharehpetian. G. B, Haque. M. T and Sabahi. M., "Reduction of dc voltage sources and switches in asymmetrical multilevel converters using a novel topology," Electric Power Systems Research, vol. 77, no. 8, pp. 1073-85, 2007.

[8] R. Melício a, V. M. F. Mendes. B and J. P. S. Catalão, "Power converter topologies for wind energy conversion systems: Integrated modeling, control strategy and performance simulation," Renewable Energy, vol. 35, pp. 2165-2174, 2010.

[9] B.Belkacem, A.K. Lahouari, M. Rahli, "SPWM and SVPWM control of a three level voltage inverter dedicated to a variable speed wind turbine," Journal of Power Technologies, vol. 97, no. 3, pp. 190-200, 2017.

[10] F. Poitiers, M. Machmoum, R. Le Doeufi and M. E. Zaim, "Control of a doubly-fed induction generator for wind energy conversion systems," IEEE Trans Renewable Energy, vol. 3, no. 3, pp. 373-378, 2001.

[11] H. S. Hamad, A. Hussein Ali, A. A. Abdulrazzaq, "An adaptable different-levels cascaded h-bridge inverter analysis for PV grid-connected systems," International Journal of Power Electronics and Drive Systems (IJPEDS), vol. 10, no. 2, 2019.

[12] B. Hamane. M. L. Doumbia, M. Bouhamida, and M. Benghanem, "Control of Wind Turbine Based on DFIG Using Fuzzy-PI and Sliding Mode Controllers," Ninth International Conference on Ecological Vehicles and Renewable Energies, pp. 1-8, 2014.

[13] A. G. Ram, S. and A. Lincoln, "Fuzzy adaptive PI controller for single input single output non-linear system," ARPN Journal of Engineering and Applied, Sciences, vol. 7, no. 10, pp. 1273-1280, 2012.

[14] T. Mesbahi, T. Ghennam and E. M. Berkouk, "A Doubly Fed Induction Generator for wind stand-alone power applications (Simulation and experimental validation)," Electrical Machines (ICEM), 2012 XXth International Conference on, pp. 2028-2033, 2012.

[15] R. Sadaoui, "Analyse et commande de la machine asynchrone à double alimentation," Université du Québec à Trois-Rivières Service de la bibliothèque, 2013.

[16] Shanzhi Li, Haoping Wang, Yang Tian, Abdel Aitouch, John Klein, "Direct power control of DFIG wind turbine systems based on an intelligent proportional-integral sliding mode control," ISA Transactions, vol. 64, pp. 431-439, 2016.

[17] K. Kerrouche, A. Mezouar and L. Boumedien, "A simple and efficient maximized power control of DFIG Variable Speed Wind Turbine," Proceedings of the 3rd International Conference on Systems and Control, 2013.

[18] A. Bouharchouche, E. M. Berkouk, T. Ghennam and B. Tabbache, "Modeling and control of a Doubly fed induction generator with battery supercapacitor hybrid energy storage for wind power applications," 2013 Fourth International Conference on Power Engineering, Energy and Electrical Drives, pp. 1392 -1397, 2013. 
[19] B. Hamane, M. L. Doumbia, M. Bouhamida and M. Benghanem, "Direct active and reactive power control of DFIG based WECS using PI and sliding mode controllers," ECON 2014-40th Annual Conference of the IEEE Industrial Electronics Society, pp. 2050-2055, 2014.

[20] A. Leredde, "Etude, Commande et Mise en Euvre de Nouvelles Structures Multiniveaux," Thèse de doctorat de l'Institut National Polytechnique de Toulouse (INP Toulouse), 2011.

[21] D. Floricau and G. Gateau "New Multilevel Converter for Industrial Medium-Voltage Applications," Journal Przeglad Elektrotechniczny (Electrical Review), pp. 26-30, 2009.

[22] F. Z. Peng, J. W. Mckeever and D. J. Adams, "A power line conditioner using cascade multilevel inverters for distribution systems," IEEE Transactions on Industry Applications, vol. 34, no. 6, pp. 1293-1298, 1998.

[23] A. Shamsul Rahimi A. Subki, and all, "Hardware implementation of single phase three-level cascaded h-bridge multilevel inverter using sinusoidal pulse width modulation," vol. 10, no. 2, 2019.

[24] J. S. Mariéthoz, "Etude formelle pour la synthèse de convertisseurs multiniveaux asymétriques: Topologies, modulation et commande," Thèse de Doctorat, Ecole Polytechnique Fédérale de Lausanne, 2005.

[25] A. Mahrous, M. K. Metwaly and N. Elkalashy, "Performance investigation of multi-level inverter for DFIG during grid autoreclosure operation," International Journal of Power Electronics and Drive Systems (IJPEDS), vol. 10, no. 1, pp. 454-462, 2019. 